\title{
Measuring the Economic and Environmental Impacts of Using Shale Oil and Gas Resources: A Computable General Equilibrium Modeling Approach
}

\author{
Farzad Taheripour*, Wallace E. Tyner \\ Department of Agricultural Economics, Purdue University, USA
}

Copyright $(\mathcal{C} 2015$ by authors, all rights reserved. Authors agree that this article remains permanently open access under the terms of the Creative Commons Attribution License 4.0 International License

\begin{abstract}
US supplies of oil and gas from shale resources have increased significantly recently and are expected to continue to grow in the future. Using these resources generates significant economic benefits for the US economy. Interestingly, prior to 2007, except for those in the industry, shale resources were not at all part of the picture. Thus, it is reasonable to consider the economic benefits of shale as a sort of dividend. This paper first quantifies the shale dividend for the US economy and then asks how much of the dividend would we have to give up to achieve significant GHG reductions defined in the President Obama's Clean Energy Standard (CES) and the Corporate Average Fuel Economy (CAFE) policies. We modify and use a well-known computational general equilibrium model to accomplish these tasks. Our results confirm that the shale technology is a game changer for the US economy yielding annual benefits between 2008 and 2035 averaging \$302 billion per year relative to 2007 . We also estimated the costs for the US economy of implementing the CES and CAFE jointly. These two policies jointly reduce the shale dividend from $\$ 302$ billion per year to $\$ 148$ billion per year on average. In other words, the shale economic gains can be used to pays the cost of emissions reduction.
\end{abstract}

Keywords Shale Oil and Gas Resources, Economic Gains, General Equilibrium, US Emission Reduction Policies

\section{Introduction}

Recent improvements in hydraulic fracturing (fracking) and horizontal drilling technologies have increased access to more unconventional oil and gas resources. These resources (including: shale and tight oil and gas) are trapped in shale formations and sandstone. Until very recent improvements in fracking and horizontal drilling technologies in the US, unconventional oil and gas resources were mainly inaccessible, except for some limited activities. The unconventional resources are found all across the world. According to the existing estimates, about 335 billion barrels of crude oil and 221 trillion cubic meters of natural gas can be extracted from shale resources at the global scale. The corresponding estimates for US are 48 billion barrels of crude oil and 32.9 trillion cubic meters of natural gas [1]. In recent years, the US supplies of oil and gas have increased significantly from shale resources due to improvements in fracking and horizontal drilling technologies. The US Department of Energy projections indicate that producing energy from shale resources will continue to grow in decades to come [2]. These projections suggest that by 2030 North America will be self-sufficient in petroleum. Currently, the US is the only country which extracts oil and gas from shale resources to any significant degree. Extracting these resources in the US will have major economic and environmental consequences for the global economy, altering the energy market at the global scale. The economic benefits from shale resources also could provide new opportunity to pursue emissions reduction polices in the US ${ }^{1}$.

The existing literature indicates that some studies have evaluated the economic gains due to expansion in producing shale gas, and some others have examined the costs of emission reduction polices in the presence of expansion in shale gas. However, to the best of our knowledge no one has examined the economic gains due to producing more oil and gas from shale resources in the absence and presence of emission reduction polices.

This paper aims to evaluate the economic gains of using shale resources for the US economy. It then asks the question of the relative size of the economic gains from shale oil and gas compared with the economic costs that would be incurred if the US were to also launch aggressive $\mathrm{CO}_{2}$ emission reduction policies. Among alternative modeling

1 Shale oil and gas technology has been controversial due to direct environmental impacts in the shale producing areas. We believe that the direct environmental issues associated with fracking are important, and must be dealt with in the regulatory structure. However, that is not the subject of this paper. 
approaches that can be used to answer these questions, given the economy wide impacts of using shale resources, a global Computable General Equilibrium (CGE) model can provide more reliable and comprehensive results. Hence, we used a modified version of a well-known global CGE model (GTAP-E, introduced in the modeling section) to achieve the goals of this paper. Since the original GTAP-E model and its data base do not cover shale oil and gas resources, as mentioned in the modeling section, we made several changes in this model to be able to conduct this research. Using the modified GTAP-E model we showed that producing more oil and gas from shale resource generates major economic gains for the US economy in the absence of any emission reduction policy. Then we showed that a carbon tax which reduces the US carbon emissions in by $27 \%$ in 2035 compared to 2007 would lead to economic losses of about $40 \%$ of the economic gains due to the expansion in shale oil and gas production.

In what follows, we first provide a brief review of the limited literature to date on the economic and environmental impacts of shale oil and gas development. Then we introduce the model and data base modifications we have done in GTAP-E to permit simulations of the shale oil and gas impacts. After that we introduce our experiments which were designed to examine the economic impacts of producing oil and gas from the shale resources in the absence and presence of emissions reduction policies. Finally, we analyze our simulation results and provide some conclusions.

\section{Literature Review}

Recently, a limited number of studies have tried to quantify the economic and environmental consequences of the new developments in the US energy market. The existing literature in this field can be divided into two categories. The first category mainly inspects the links between producing more shale gas with US emission reduction polices. The second group tries to measure the economic gains due to producing more gas from shale resources in the US.

The expansion in US gas production from shale resources provides an opportunity for the US economy to move away from coal (a very dirty source of energy) and use more gas (a cleaner source of energy). However, the extent to which this shift may occur in the real world will depend on future emissions reduction policies. Several papers have examined this topic. These papers usually do not take into account future growth in production of oil from shale resources. We review three main papers from this group. Brown et al. [3] have examined several energy and climate policy scenarios using an energy-economy market equilibrium model and concluded that the growth in supply of natural gas from shale resources in combination with carbon polices could support the US economy to achieve low-carbon standards in future. Paltsev et al. [4] have studied the growth in the US natural gas production from shale resource as well. These authors have focused on the trade, production and use of natural gas in future decades. They used two CGE models and showed that even in the absence of additional GHG abatement policies, production and use of gas in 2050 will be higher than today and that shale gas will help to achieve a lower level of emissions. Jacoby et al. [5] also examined the impacts of the expansion in US shale gas on US energy and environmental policy and reached similar conclusions.

In an early research in this area the IHS Global Insight Inc. [6] projected the economic impacts of the expansion in supply of gas for the US economy until 2035 using a macroeconomic model of the US economy in combination with an industry model. This research projected that about $\$ 1.9$ trillion will be invested in shale gas during the time period of 2010-35. They also projected that the growth in shale gas industry will add 0.9 million and 1.6 million job opportunities in the US in these years. The simulation results obtained from this research show that the growth in shale gas will increase the US GDP by $\$ 118$ billion and $\$ 231$ billion in 2015 and 2035, respectively. In a different paper the Citi GPS [7] has also estimated the gains due to growth in shale gas in the near future in the US. Again using a US macro model this research concluded that the growth in gas supply could improve the US GDP up to $3 \%$ in 2020. Arora [8] using a US macro CGE model concluded that the expansion in supply of natural gas will improve the US GDP by a small to moderate rate with a full employment assumption. Sarica and Tyner [9] used a hybrid model named MARKAL-Macro to evaluate the impacts of a carbon tax and other policies on the US energy mix as well as economic impacts on the economy. They find that a policy such as the clean energy standard proposed by President Obama and the Corporate Average Fuel Economy (CAFE) rules would substantially change the energy source mix in the electricity sector by 2035 with coal being largely displaced by natural gas, wind energy, and other sources. They also find that such an emission reduction policy would lead to a 1-2\% GDP reduction depending on how it was implemented.

While these papers provided important analyses on the impacts of the expansion in shale gas, they missed the impacts of simultaneous growths in both shale oil and gas. They ignored the interaction between economic gains and environmental policies in the presence of expansion in using shale resources. In a recent study, Taheripour et al. [10] using a modified version of the GTAP-E model evaluated the economic gains due to increases in oil and gas production from shale resources for the US economy until 2035. Henceforth we refer to this paper as TTS. These authors developed scenarios with and without expansion in using shale resources and showed that the US GDP on average would be $2.2 \%$ higher during the time period of $2008-35$ compared with its original level in 2007. These authors also have shown that with no regulation in place, producing more oil and gas from shale resources could increase US total $\mathrm{CO}_{2}$ emissions. Like other papers in this area, these authors also did not take into account the possible interaction between economic gains and environmental policies in the presence of expansion in using shale resources.

In this paper, we extend the work developed by TTS to study the extent to which emissions reduction policies affect 
the economic impacts of expansion in using shale resources. The existing literature confirms that in the presence of proper emissions reduction policies, the expansion in US gas production from shale resources can help the US economy to produce fewer emissions in future. On the other hand, the existing estimates indicate that producing more oil and gas from shale resources generates significant economic gains for the US economy. It is also common knowledge that the emissions reduction polices are not free and generate some welfare losses. Thus, the country is clearly presented with an economic gain from shale resources, and the opportunity to use part of that gain if we choose to reduce greenhouse gas (GHG) emissions. Hence, the question that we try to answer in this paper is: What are the relative magnitudes of the shale benefits and the economic costs of GHG reduction? We find that half or less of the shale dividend would be required to achieve the GHG reduction.

\section{Methods}

\subsection{Modeling Background}

To capture the economy-wide impacts of using shale oil and gas resources, we extensively modified and used an advanced version of the standard GTAP model developed by Hertel [11]. This is a well-known global CGE model which has been broadly used in a wide range of research on economic, environmental, and energy topics. GTAP traces production, consumption, and trade of a wide range of goods and services at a global scale and by region. As represented in Figure 1, in this model in each country (e.g., USA) a regional household collects all the regional incomes and spends those over three expenditure categories: private household (consumer), government, and savings. The model determines the household and government demands for goods and services and traces saving and investment in each region and at the global scale. The model divides economic activities into several sectors. In each sector a representative firm maximizes profits subject to a production function that combines primary factors and intermediate inputs to produce a final good. Firms pay wages/rental rates to the regional household in return for the employment of land, labor, capital, and natural resources. On the other hand, firms sell their output to other firms (as intermediate inputs), private households, government, and investment. Since this is a global model, firms also export the tradable commodities and import the intermediate inputs from other regions. These goods are assumed to be differentiated by region, so the model can track bilateral trade flows. The rest of the world gets revenues by exporting to private households, firms and government. This rest of world composite is actually made up of many other regions. The supply and demand functions along with market clearing conditions and other relationships implemented in this model are presented in Hertel [11].

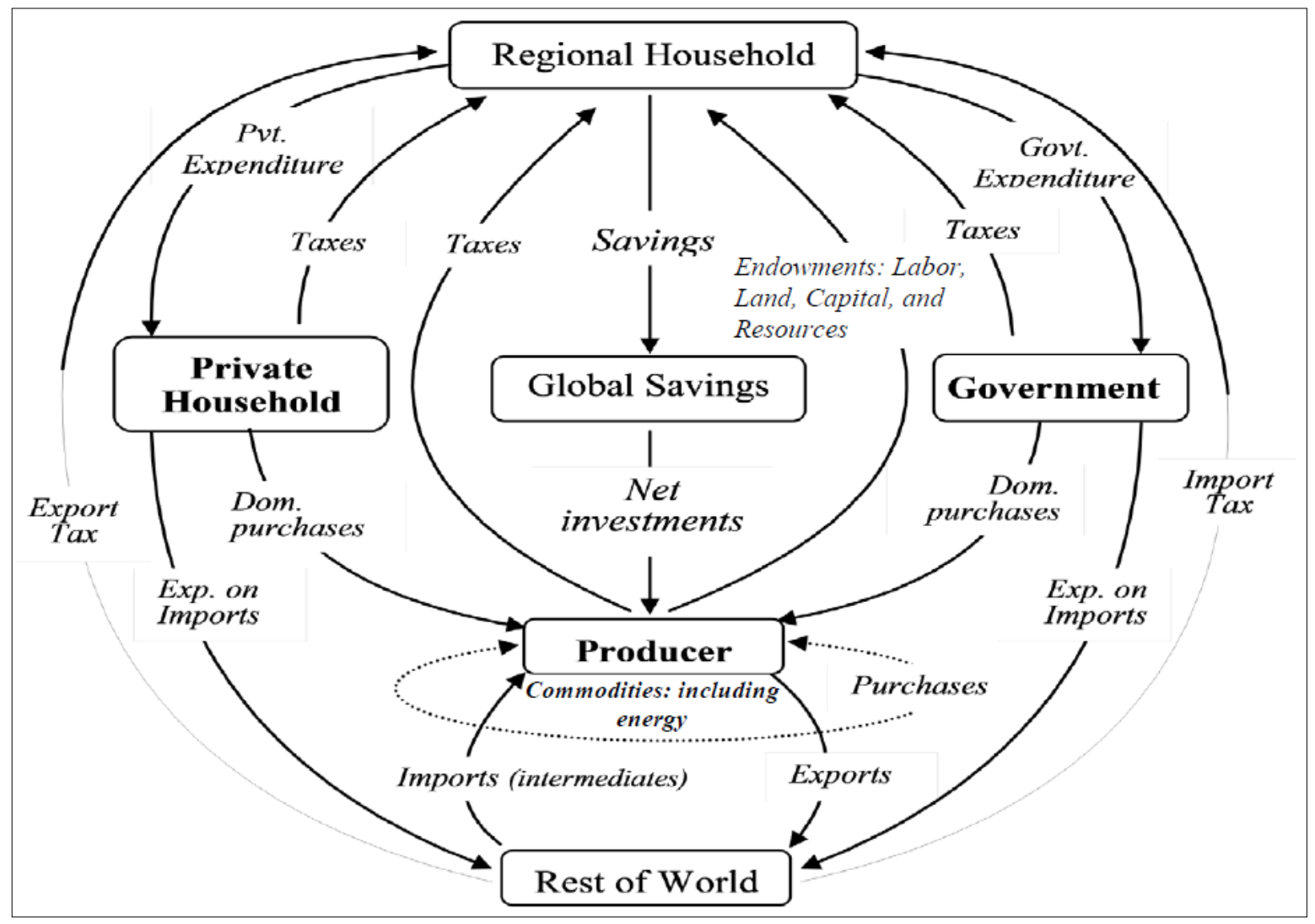

Figure 1. An overview of standard GTAP model: Hertel [11] 
GTAP-E, a special version of the standard GTAP, provides a comprehensive framework to examine the sectoral and economy wide consequences of changes in markets for energy sources and products (such as crude oil, gas, coal, refined petroleum products, and electricity) and/or emissions reduction, energy, and trade policies. Burniaux and Truong [12] and McDougall and Golub [13] outlined the details of this model.

To evaluate the economic impacts of expansion in production of oil and gas from shale resources we made major changes in the GTAP-E model and its data base. TTS briefly introduced some of these modifications. In this section we document those modifications in greater detail. We made some changes in the model to examine the interactions between the US emissions reduction policies and the expansion in production of oil and gas from shale resources. These model modifications are also introduced in this section.

\subsection{Modifications in GTAP-E Model and its Data Base}

\subsubsection{Data base modifications}

The GTAP data base version 8 [17], which represents the world economy in 2007 (classified into 129 countries/regions and 57 commodities) is used in this paper. This data set includes regional input-output tables along with comprehensive data on trade, energy production and consumption, and greenhouse gas emissions. The following major corrections and modifications were made in this data base to make the data base more consistent with real world observations: 1) Biofuels were added to the data base; 2) Regional monetary values of gas production and consumption and of gas purchased by the gas distribution sector were corrected; 3) Natural resources were divided into different categories.

The standard GTAP data bases do not explicitly represent production, consumption and trade of biofuels. Given that several countries were producing large amounts of biofuels in 2007, following Taheripour et al. [14], we introduced production, consumption, and trade of biofuels including ethanol produced from food grains and sugarcane and biodiesel produced from oilseeds into the GTAP data base. This is an important modification because it allows us to capture the interplays between biofuels and fossil fuels (including oil and gas produced from shale resources) in the presence of emission reduction polices in our experiments.

Based upon careful examination of the detailed GTAP data base, we learned that it under estimates the regional monetary values of gas production and consumption and of gas purchased by the gas distribution sector ("gdt") as explained in detail in Appendix A. Since expansion in using shale resources will increase the supply of gas and its consumption, we fixed these issues to provide more accurate estimates of monetary values of future expansion in supply of gas, as explained in Appendix A.

The last data base modification divides the payments to natural resources into 5 different categories. This is a simple, but very important modification for this research. The standard GTAP data base defines a common pool of natural resources, and producers share the pool. Then the standard GTAP model considers natural resources as a sluggish endowment with limited movement across sectors. We altered this set up to model the expansion in oil and gas reserves due to improvements in fracking and horizontal drilling technologies and define sector specific resources as explained in the next section. To accomplish this task we divided natural resources into 5 different groups of natural resources including fishery, coal, oil, gas, and other resources.

\subsubsection{Model Modifications: Revising firms' demand nesting structure}

The GTAP-E model uses nested constant elasticity of substitution production functions to represent firms' behavior and determine their demands for intermediate and primary inputs including capital, labor, land, and resources as shown in Figure 2. At the very bottom of this production tree, firms bundle crude oil, natural gas, and petroleum products with the substitution elasticity of $\sigma_{\text {ELNCOAL }}$ to create non-coal energy sources. At the higher level the non-coal and coal items are combined with the substitution elasticity of $\sigma_{\text {ELNEL }}$ to generate non-electricity energy sources. At a higher level, electricity and non-electricity items are combined with the substitution elasticity of $\sigma_{\mathrm{ELEN}}$ to form the composite of all energy items under one category. Then at one level higher capital and energy are combined to allow substitution between these items with the elasticity of $\sigma_{\text {ELKE }}$. At the next higher level, primary inputs such as land, labor, and resources are mixed to obtain the composite of value added and energy with the substitution elasticity of $\sigma_{\text {ESUBVA }}$. Finally, at the highest level of the tree the mix of value added and energy is combined with the mix of other intermediate inputs with the substitution elasticity of $\sigma_{\text {ESUBT }}$ to produce the final product. As shown in Figure 2, the energy and non-energy intermediate inputs can be obtained either from domestic or foreign markets.

While the GTAP-E model makes the substitution among energy items possible, its nesting structure does not reflect the recent evolution in the energy market. In recent years a direct and major substitution has been observed between gas and coal. Sarica and Tyner [9] have demonstrated this fact using a bottom up energy model. The original nesting structure implemented in the GTAP-E model ignores this reality, because it first substitutes oil and gas and then combines the mix of gas and oil with coal. Given the expected expansion in gas resources, the substitution between coal and gas is anticipated to prevail in the future as well. Hence, we made proper changes in the GTAP-E firms' production functions to represent direct substation between coal and gas. Since we have introduced biofuels into our data base and given that the GTAP-E model does not cover biofuels, following Hertel el al. [15] we introduced biofuel in the revised model as well. The new production nesting 
structure is presented in Figure 3. At the very bottom nest, biofuels are introduced in the nest. Then unlike the original model coal and gas are mixed directly to represent the direct substitution between gas and coal. Then at a higher level the combination of coal-gas substitutes with oil and petroleum products to generate the non-electricity energy input. From this point to the top production function we preserved the original GTAP-E nesting structure.
The production functions associated with the original and modified nesting strictures presented in figures 2 and 3 are shown in Appendix B. The first table of this appendix represents the Constant Elasticity of Substitution (CES) production functions used in the original GTAP-E model, and the second table demonstrates the modified CES production functions.

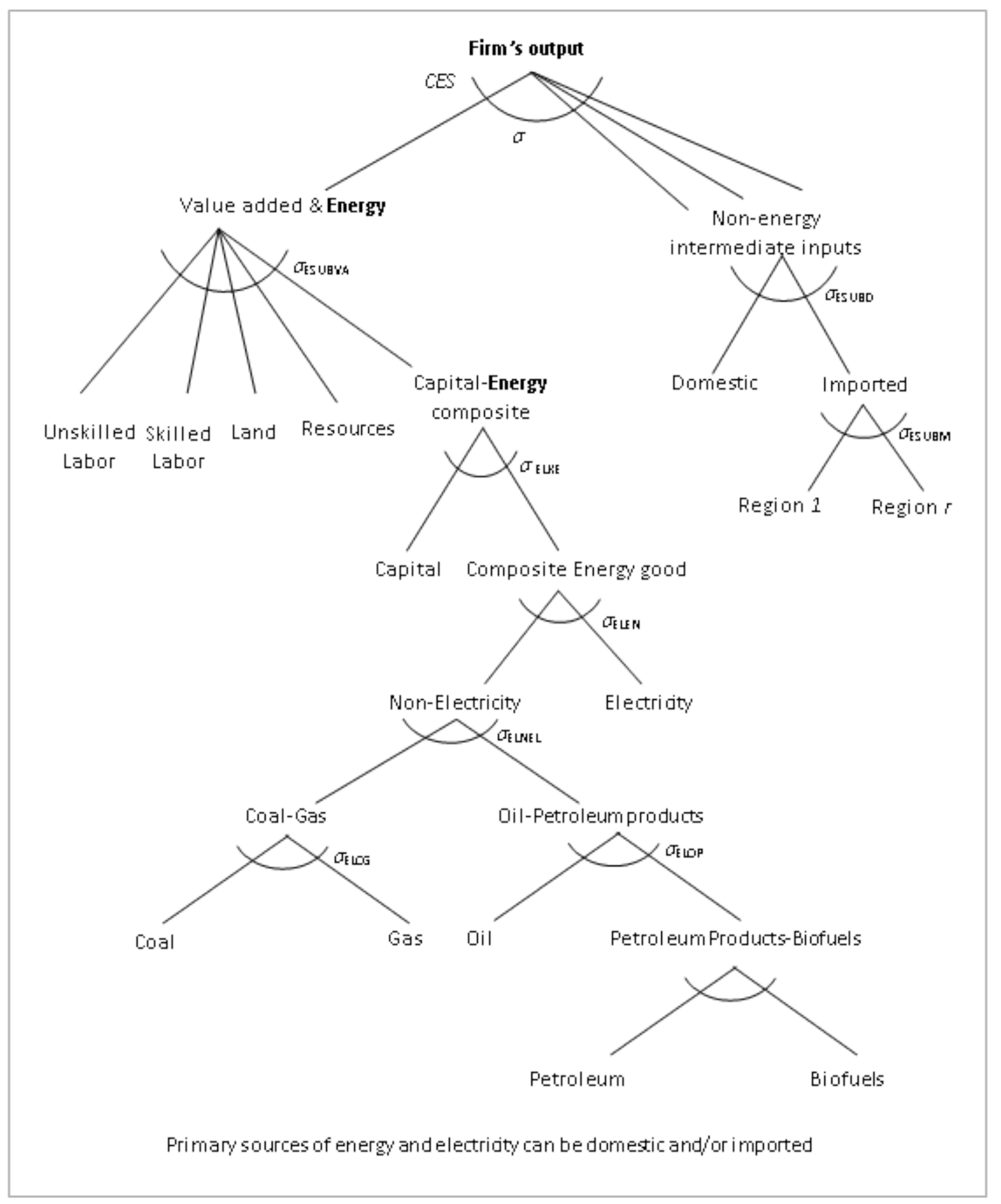

Figure 2. Original GTAP-E Production Nesting Structure 


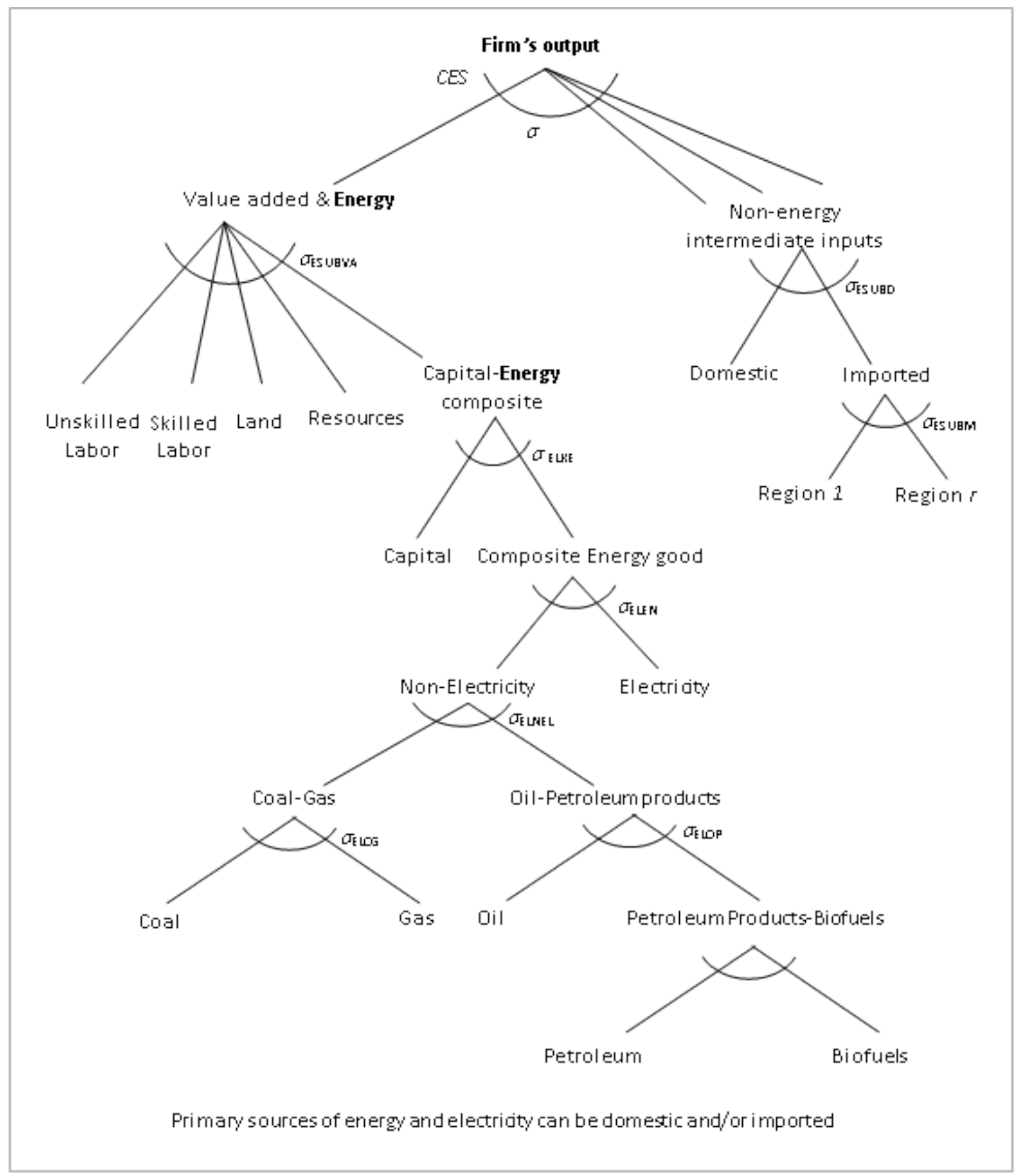

Figure 3. Modified GTAP-E Production Nesting Structure

\subsubsection{Model Modifications: Other Major Modifications in GTAP-E model}

The GTAP-E model and its data base do not distinguish between alternative natural resources and bundle all types of natural resources under one category. We altered this set up and distinguished between fossil fuels and other resources to model the expansion in shale resources. Then we used the information developed by the US Department of Energy [2] to determine the magnitudes of the expansions in these resources over time.
The original GTAP-E model only allows the users to use a uniform emissions tax (usually known as the least cost emission reduction) on all goods and services to reduce GHG emissions. This set up is not flexible enough to model the impacts of US emission reduction policies which are more complex than a simple uniform emission tax. The US has a Corporate Average Fuel Economy Standard (CAFE) that takes fleet fuel economy from 27.5 miles per gallon (MPG) today to 54 MPG by 2025 . In addition, the US has a policy to reduce GHG emissions from the electricity sector. The electricity and transportation sectors are the major GHG 
emitters in the US with 40 and 34 percent of total emissions respectively [16]. Thus it is understandable that these sectors would be targeted by current US policy. The combined goal of the regulatory policies (including the average fleet efficiency (CAFE) standard, renewable fuel standard (RFS), and clean energy standard (CES) for electricity is to reduce $\mathrm{CO}_{2}$ emissions in 2035 by $27 \%$, compared to 2007 (Sarica and Tyner, 2013). We altered the GTAP-E model to examine the joint impacts of reductions in emissions generated by the transportation and electricity sectors.

Finally, the original GTAP-E model assumes that all primary factors of production including labor, land, capital, and natural resources are fully employed in the short run. This is not a plausible assumption for a relatively long time period, as using shale resources affects the labor market in the long run. Therefore, unlike the GTAP-E model, we assumed that supplies of labor and capital grow as the production of oil and gas from shale resources expand. We tuned the supply elasticities of labor and capital according the numerical results reported in Citi GPS [7].

\subsection{Designed Experiments}

To achieve the goals of this paper, we developed the following four experiments/cases:

Case 1: Expansion in supplies of oil and gas produced from shale resources with no carbon emission reduction policy in place. This experiment is designed to capture the economic impacts of producing more oil and gas from shale resources, while we assume that the government does not control emissions. In this experiment we shock production of oil and gas (induced by technological progress in these sectors) according to the DOE projections for oil and gas produced from shale resources in 2007-2035. Given these shocks our model projects changes in the endogenous economic variables compared with the base year (2007).

Case 2: Expansion in supplies of oil and gas produced from shale resources with a uniform economy-wide carbon tax to cut emissions by 27\% compared to 2007. In this experiment we repeat the first experiment while we assume that the government imposes a non-discriminatory uniform emissions tax across all sectors, commodities, and sources of emissions to reduce emissions by $27 \%$ compared to the base year. Therefore, in this simulation two forces determined the results: 1) increases in oil and gas production from shale resources compared to the base year and 2) a uniform emissions reduction policy to reduce emissions by $27 \%$ again compared to the base year (2007).

Notice that the emissions reduction policy which we used in this experiment is usually referred to as the least cost emissions reduction policy. However, currently the US does not pursue this policy to reduce GHGs emissions. Instead, the US concentrates on CAFE, RFS, and CES policies to reduce emissions. The next experiment represents the impacts of these policies.

Case 3: Expansion in supplies of oil and gas produced from shale resources with a carbon tax imposed only on electricity and transportation sectors to cut emissions by $27 \%$ compared to 2007. This experiment is similar to the second experiment, but instead of using a uniform economy-wide emission tax, imposes the emission tax only on the electricity and transportation sectors to achieve the $27 \%$ emission reduction targets. The implemented policy in this experiment represents the joint impacts of CAFE, RFS, and CES policies.

Case 4: Expansion in supplies of oil and gas produced from shale resources with a carbon tax imposed only on electricity sector to cut emissions by 27\% compared to 2007. This experiment is similar to the third one, but transportation is the only sector which bears the burden of the emission tax.

All of the above experiments consider a goal of $27 \%$ reduction in carbon emissions for the US. To examine the sensitivity of the results with respect to this target we repeated the second experiment (i.e. case 2) under several emissions reduction targets, from $0 \%$ to $60 \%$ in $15 \%$ increments. The next section presents the results.

\section{Results}

To concentrate on the economic gains of producing more oil and gas from shale resources under alternative emission reduction scenarios, we only report the average results for 2008-2035 compared with the base year (2007).

\subsection{Case 1 - Shale Expansion Only}

The first block of Table 1 provides the percentage change in output, prices, and trade balance for major US commodity groups for case 1 . As would be expected, the biggest changes are in output, prices, and trade of oil and gas. Oil and gas production are expected to increase $31 \%$ and $39 \%$, respectively. Their prices fall $8 \%$ and $12 \%$ correspondingly. With no emission reduction policy in place, the growth in gas and oil production leads to a negligible reduction in coal production (1.4\%). This means that with no emission reduction policy, the US economy only reduces coal production by a small amount due to expansion in using shale resources. Indeed, the negative impact on coal demand due to substitution of cheap oil and gas is counterbalanced by the positive impact of increased income, which increases the demand for energy. As shown in the next section, production of coal drops significantly in the presence of emissions reduction policies.

As shown in the first block of Table 1, with no emission reduction target, producing more oil and gas from shale resources improves the US trade balances of oil, gas, and petroleum products by $\$ 20.7$ billion, $\$ 32.8$ billion, and $\$ 2.9$ billion, respectively. The only other major change on the trade side is a reduction in the trade balance for all the industrial sectors. The major driver of this change is the increase in GDP and welfare induced by the shale oil and gas expansion, which increases the demands for industrial products. With this increased demand, imports increase more than exports. 
A Computable General Equilibrium Modeling Approach

Table 1. Selected Key Simulation Results for Cases 1 and 2

\begin{tabular}{|c|c|c|c|c|c|c|}
\hline \multirow[b]{2}{*}{ Sector } & \multicolumn{3}{|c|}{ Case 1} & \multicolumn{3}{|c|}{ Case 2} \\
\hline & Outputs \%Change & Prices $\%$ Change & $\begin{array}{l}\text { Trade Balance } \\
\text { Million Dollar }\end{array}$ & Outputs \%Change & Prices \%Change & $\begin{array}{l}\text { Trade Balance } \\
\text { Million Dollar }\end{array}$ \\
\hline Crops & 0.16 & 2.9 & $-1,414$ & -0.36 & 0.96 & -998 \\
\hline Livestock & 1.46 & 0.67 & -228 & 0.64 & 0.71 & -172 \\
\hline Forestry & 0.98 & 0.89 & -62 & -0.10 & 0.47 & -20 \\
\hline Fishing & 0.76 & 1.20 & -68 & 0.03 & 1.26 & -49 \\
\hline Food & 1.63 & 0.44 & $-3,234$ & 0.77 & 0.65 & $-2,935$ \\
\hline Coal & -1.40 & 0.27 & -182 & -35.14 & -4.68 & 912 \\
\hline Oil & 30.80 & -7.82 & 20,703 & 30.80 & -10.12 & 40,103 \\
\hline Gas & 38.90 & -11.70 & 32,811 & 38.90 & -13.28 & 42,019 \\
\hline Gas Distribution & 9.43 & -6.83 & 297 & 2.20 & -6.50 & 769 \\
\hline Oil Products & 5.62 & -3.56 & 2,890 & 0.69 & -3.86 & 6,563 \\
\hline Biodiesel & 5.29 & 0.59 & 0 & -1.09 & 0.97 & 0 \\
\hline Ethanol & 5.29 & 0.30 & 0 & -1.09 & 2.01 & 0 \\
\hline Electricity & 2.36 & -1.28 & -6 & -4.61 & 8.97 & $-1,082$ \\
\hline Chemical Ind. & 0.81 & -0.02 & $-8,303$ & -1.17 & 0.56 & $-11,244$ \\
\hline Energy Intensive Ind. & 0.70 & 0.01 & $-3,506$ & -2.18 & 1.15 & $-6,488$ \\
\hline Other Industries & 1.26 & 0.43 & $-65,494$ & -0.40 & 0.55 & $-42,786$ \\
\hline Transportation & 2.52 & -0.75 & $-1,202$ & -0.36 & 1.82 & $-6,822$ \\
\hline Services & 2.05 & 0.64 & $-15,523$ & 1.19 & 0.54 & $-9,778$ \\
\hline
\end{tabular}

Source: Simulation results obtained from case 1. Each figure represents average change for the time period of 2008-2035 compared with the base year of 2007.

Table 2. Key Economy-Wide Simulation Results for Cases 1 and 2

\begin{tabular}{|c|c|c|c|c|}
\hline \multirow[b]{2}{*}{ Country or Region } & \multicolumn{2}{|c|}{ Case 1} & \multicolumn{2}{|c|}{ Case 2} \\
\hline & $\begin{array}{l}\text { Change in Welfare in } \\
\text { Million Dollar }\end{array}$ & $\begin{array}{l}\text { \% Change in } \\
\text { GDP }\end{array}$ & $\begin{array}{l}\text { Change in Welfare in } \\
\text { Million Dollar }\end{array}$ & $\%$ Change in GDP \\
\hline USA & 302,259 & 2.23 & 178,087 & 1.18 \\
\hline EU27 & 5,186 & 0.02 & 13,902 & 0.05 \\
\hline Brazil & -232 & -0.01 & 124 & 0.01 \\
\hline Canada & $-3,402$ & 0.00 & $-4,744$ & 0.01 \\
\hline Japan & 2,426 & 0.02 & 5,567 & 0.05 \\
\hline China \& Hong Kong & 1,017 & 0.01 & 1,197 & 0.00 \\
\hline India & 710 & 0.03 & 1,732 & 0.06 \\
\hline Central America & $-1,543$ & -0.10 & $-3,054$ & -0.15 \\
\hline South America & $-1,425$ & -0.01 & $-2,444$ & -0.01 \\
\hline East Asia & 1,235 & 0.03 & 2,249 & 0.06 \\
\hline Malaysia \& Indonesia & -517 & -0.01 & -770 & -0.02 \\
\hline Rest of South East Asia & -190 & 0.00 & -126 & 0.01 \\
\hline Rest of South Asia & 267 & 0.01 & 464 & 0.03 \\
\hline Russia & $-4,027$ & -0.11 & $-6,582$ & -0.17 \\
\hline Other CEE/CIS & -877 & -0.02 & -924 & -0.02 \\
\hline Other Europe & $-1,229$ & -0.01 & $-1,901$ & 0.00 \\
\hline Middle East \& north Africa & $-7,878$ & -0.02 & $-13,427$ & -0.03 \\
\hline Sub Saharan Africa & $-2,449$ & -0.03 & $-4,142$ & -0.04 \\
\hline Oceania & -548 & -0.01 & -493 & -0.01 \\
\hline Total & 288,783 & NA & 164,715 & NA \\
\hline
\end{tabular}

Source: Simulation results obtained from case 1. Each figure represents average change for the time period of 2008-2035 compared with the base year of 2007. 
The first block of Table 2 provides the changes in welfare (measured in terms of Equivalent Variation 2 (EV)) and GDP by region for case 1 . This block shows that in the absence of environmental regulation, producing more oil and gas from shale resources improves US welfare by more than $\$ 300$ billion per year relative to the 2007 level. Similarly US GDP increases, on average by $2.2 \%$ compared with 2007 . The main regions negatively impacted by the expansion in using US shale resource are the Middle East and Russia major oil and gas exporters. Canada, also an oil exporting county, suffers from higher US production. The European Union is positively impacted. In total, the US shale oil and gas expansion reduces welfare by about $\$ 14$ billion in all of the rest of world, a very small amount. So the bulk of the impact of the US shale oil and gas expansion is within the US. Finally, the first block of Table 1 indicates that producing more oil and gas from shale resources in US barley affects GDP of other countries. Of course some countries gain and some loss.

\subsection{Case 2 - Shale Expansion Plus a Uniform Economy Wide Carbon Tax}

As shown in the second block of Table 2 in case 2, when we add the economy wide uniform carbon tax, the welfare gains for the US drop to $\$ 178$ billion, a drop of $41 \%$ compared with the welfare gains of case 1 . The GDP level increase falls from 2.2 to $1.2 \%$ as well. This may seem like a large loss, but it is a glass half empty or glass half full question. Yes, $41 \%$ of the shale gain is lost, but substantial reduction in GHG emissions has been achieved. While we do not have quantitative estimates of the benefits of avoiding the adverse impacts of climate change, they clearly cannot be ignored. Another way to interpret these results is that we can at the same time have more fossil energy and achieve substantial economic gains, while also reducing GHG emissions $27 \%$ from the 2007 base. As shown the second block of Table 2, imposing an emission reduction policy in the US decreases welfares of oil exporting regions (Middle East \& North Africa and Russia) and also Canada significantly, due to lower emission intensity. In this case the European Union gains more, due to lower emission intensity.

The second block of Table 1 represents changes in US outputs, prices, and commodity trade balances for case 2 . The important differences between these results and case 1 are as follows:

- Coal output drops by $1.4 \%$ in case 1 , and it falls by $35.1 \%$ in the carbon tax case. This means that production of coal goes down significantly in the presence of the carbon tax. This result is consistent with prior research on the carbon tax [9], using a completely different modeling framework. The

2 In general, in a CGE modeling framework usually EV measures changes in consumers' and producers' surpluses due to changes in policy variables (such as tax) and/or changes in exogenous variables (such as technological progress). The GTAP model includes a module which calculates EV. For more information see Huff et al. [18] simulation results also show that in the presence of emissions reduction policy, the US even exports a portion of its coal production to other countries as well. On average the net trade of coal increases by $\$ 912$ million in the presence of the carbon tax.

- Trade balances for oil, gas, and petroleum products improve to $\$ 40$ billion, $\$ 42$ billion, and $\$ 6.6$ billion, due to reduction in US fuel consumption with the carbon tax.

- Electricity output increases $2.4 \%$ in case 1 , but falls $4.6 \%$ with the carbon tax

- While all the industrial sectors grew in the shale expansion case, they all contract a bit in the carbon tax case.

- Coal price was relatively flat in the shale expansion case but falls $4.7 \%$ with the carbon tax.

- Electricity price drops by $1.3 \%$ in case 1 but increases $9 \%$ with the carbon tax.

- The industrial trade balance improves relative to the shale expansion case because incomes are not rising as much.

\subsection{Case 3 - Shale Expansion Plus Carbon Tax Imposed Only on Electricity and Transportation}

In case 3 we consider an option that approximates current US energy policy; that is, expansion of shale oil and gas resources along with regulations on electricity and transport emissions that together achieve the $27 \%$ reduction in emissions. In essence, this policy concentrates all the emission reduction in the two sectors that together represent $71 \%$ of all GHG emissions. With this policy, as shown in the first block of Table 4, the US welfare gain falls from $\$ 302$ billion in case 1 and $\$ 178$ billion in case 2 to $\$ 148$ billion. Cases 1 and 2 had GDP gains of 2.2 and $1.2 \%$, whereas case 3 has a gain of $1 \%$, as shown in the first block of Table 4 . The US welfare gain in case 3 is $\$ 30$ billion less than the gain from case 2 . This indicates that by avoiding the more efficient economy-wide carbon tax and instead using regulatory measures to achieve the same objective, the welfare cost to the economy is about $\$ 30$ billion/year.

The first block of Table 3 represents changes in outputs, prices, and trade balances for case 3. The main differences compared to the first two cases are as follows:

- Coal output falls even further to $-39 \%$. This difference is to be expected since more of the emission reduction is forced on the electricity sector and that reduces coal production and consumption by large quantities. US net coal exports increase from $\$ 912$ million in case 2 to $\$ 1147$ in case 3 .

- All the fossil energy prices fall significantly.

- Electricity price goes up $12.5 \%$ compared with $9 \%$ in the carbon tax case.

- All the industrial prices go up more than in the carbon tax case.

- The industrial trade balance improves a bit compared with the carbon tax case. 
A Computable General Equilibrium Modeling Approach

Table 3. Selected Key Simulation Results for Cases 3 and 4

\begin{tabular}{|c|c|c|c|c|c|c|}
\hline \multirow[b]{2}{*}{ Sector } & \multicolumn{3}{|c|}{ Case 3} & \multicolumn{3}{|c|}{ Case 4} \\
\hline & Outputs $\%$ Change & Prices \%Change & $\begin{array}{l}\text { Trade Balance } \\
\text { Million Dollar }\end{array}$ & Outputs $\%$ Change & Prices \%Change & $\begin{array}{c}\text { Trade Balance Million } \\
\text { Dollar }\end{array}$ \\
\hline Crops & 0.13 & 1.44 & -648 & 0.16 & 1.66 & -671 \\
\hline Livestock & 0.60 & 0.45 & -126 & 0.75 & 0.31 & -109 \\
\hline Forestry & -0.15 & 0.35 & -17 & 0.02 & 0.36 & -19 \\
\hline Fishing & 0.48 & 0.38 & -27 & 0.51 & 0.45 & -31 \\
\hline Food & 0.70 & 0.42 & $-2,189$ & 0.83 & 0.29 & $-1,918$ \\
\hline Coal & -38.98 & -5.71 & 1,147 & -42.60 & -7.09 & 1,426 \\
\hline Oil & 30.80 & -9.29 & 33,573 & 30.80 & -7.79 & 21,410 \\
\hline Gas & 38.90 & -12.14 & 35,638 & 38.90 & -11.99 & 34,985 \\
\hline Gas Distribution & 10.18 & -6.93 & 516 & 11.41 & -6.84 & 301 \\
\hline Oil Products & 2.32 & -4.05 & 6,505 & 5.36 & -3.28 & 2,544 \\
\hline Biodiesel & 5.17 & 1.09 & 0 & 4.63 & 1.25 & 0 \\
\hline Ethanol & 5.17 & 2.46 & 0 & 4.63 & 3.00 & 0 \\
\hline Electricity & -8.02 & 12.52 & $-1,370$ & -9.64 & 15.69 & $-1,681$ \\
\hline Chemical Ind. & -0.77 & 0.34 & $-8,109$ & -0.64 & 0.35 & $-8,147$ \\
\hline $\begin{array}{l}\text { Energy Intensive } \\
\text { Ind. }\end{array}$ & -1.60 & 0.76 & $-4,491$ & -1.27 & 0.69 & $-4,393$ \\
\hline Other Industries & -0.45 & 0.46 & $-34,496$ & -0.17 & 0.38 & $-33,839$ \\
\hline Transportation & -0.99 & 2.77 & $-8,669$ & 1.15 & -0.76 & 130 \\
\hline Services & 0.90 & 0.49 & $-8,345$ & 0.97 & 0.46 & $-8,727$ \\
\hline
\end{tabular}

Source: Simulation results obtained from case 1. Each figure represents average change for the time period of 2008-2035 compared with the base year of 2007.

Table 4. Key Economy-Wide Simulation Results for Cases 3 and 4

\begin{tabular}{|c|c|c|c|c|}
\hline \multirow[b]{2}{*}{ Country or Region } & \multicolumn{2}{|c|}{ Case 3} & \multicolumn{2}{|c|}{ Case 4} \\
\hline & $\begin{array}{l}\text { Change in Welfare in } \\
\text { Million Dollar }\end{array}$ & $\%$ Change in GDP & $\begin{array}{l}\text { Change in Welfare in } \\
\text { Million Dollar }\end{array}$ & $\%$ Change in GDP \\
\hline USA & 148,373 & 0.97 & 150,779 & 1.04 \\
\hline EU27 & 11,919 & 0.04 & 8,324 & 0.03 \\
\hline Brazil & 103 & 0.01 & 105 & 0.00 \\
\hline Canada & $-4,162$ & 0.01 & $-3,498$ & 0.00 \\
\hline Japan & 4,651 & 0.04 & 3,404 & 0.03 \\
\hline China \& Hong Kong & 997 & 0.00 & 760 & 0.00 \\
\hline India & 1,449 & 0.05 & 971 & 0.04 \\
\hline Central America & $-2,522$ & -0.13 & $-1,915$ & -0.10 \\
\hline South America & $-2,068$ & -0.01 & $-1,373$ & -0.01 \\
\hline East Asia & 1,851 & 0.05 & 1,408 & 0.03 \\
\hline Malaysia \& Indonesia & -661 & -0.02 & -565 & -0.01 \\
\hline Rest of South East Asia & -155 & 0.01 & -201 & 0.00 \\
\hline Rest of South Asia & 391 & 0.03 & 286 & 0.02 \\
\hline Russia & $-5,451$ & -0.14 & $-4,138$ & -0.12 \\
\hline Other CEE/CIS & -750 & -0.02 & -697 & -0.02 \\
\hline Other Europe & $-1,572$ & 0.00 & $-1,190$ & -0.01 \\
\hline Middle East \& north Africa & $-11,363$ & -0.02 & $-7,800$ & -0.02 \\
\hline Sub Saharan Africa & $-3,521$ & -0.03 & $-2,364$ & -0.02 \\
\hline Oceania & -452 & -0.01 & -431 & -0.01 \\
\hline Total & 137,056 & NA & 141,867 & NA \\
\hline
\end{tabular}

Source: Simulation results obtained from case 1. Each figure represents average change for the time period of 2008-2035 compared with the base year of 2007. 


\subsection{Case 4 - Shale Expansion Plus Carbon Tax on Electricity Sector Alone}

This case warrants a look because some in the US believe that the US fuel economy standards may be weakened because achieving the very high fleet average fuel economy would be very expensive. 3 If so, much of the remaining emissions reduction policy would be on the electricity sector, as we envision in case 4 . Our simulation results indicate that there are small difference between the results of cases 3 and 4 , as shown in tables 3 and 4 . In case 4, the US welfare gain slightly increases to $\$ 151$ billion, not very different from case 3. In essence it is less expensive to achieve emission reductions in electricity than transportation. The GDP change rounded is the same $1 \%$. Other important differences are as follows:

- Coal output falls further by $42.6 \%$ of the base case. Coal price which was falling by $4.7 \%$ and $5.7 \%$ in the cases 2 and 3 falls further by $7.8 \%$, in this case. Also US coal net exports increase to $\$ 1,426$ million. This means that the US electricity sector will move away from coal consumption in this case more than the other cases explained above. Instead more coal will be exported in this case.

- Electricity output falls more as would be expected, down $9.6 \%$, while electricity price jumps by $15.7 \%$.

All the changes are in the expected directions. This last policy concentrates all the emission reductions in the electricity sector, so most of the impacts are on coal, electricity, and industry.

\subsection{Sensitivity Analysis on Welfare Changes and Size of Emission Reduction Targets}

We now examine the sensitivity of welfare gains with respect to the emission reduction targets. For this purpose, we repeat the second experiment (case 2) for five additional levels of emissions reductions targets of $15 \%, 30 \%, 45 \%$, and $60 \%$ for the year of 2035 compared to 2007 . Table 5 represents results of this sensitivity test. Net economic gains due to the expansion in shale resources decrease as we increase the size of emission target, as would be expected. This table shows that with zero emissions reduction target the welfare gain is about 302 billion, as we observed for case 1. The gain drops as we increase the size of emission reduction target from zero to $60 \%$ with an increasing rate. For the $15 \%, 30 \%, 45 \%$ and $60 \%$ emissions reduction targets, the welfare gains are $\$ 233$ billion, $\$ 159$ billion, $\$ 42$ billion and $-\$ 158$ billion, respectively. As shown in table 5, the reduction in welfare gain is about 69 billion for the first $15 \%$. This size of reduction in welfare for the last $15 \%$ is about

3 The CAFE standard goal is to reach 54.5 MPG in 2025. Analysis of the CAFE standard suggests that moving beyond $45 \mathrm{MPG}$ will be too expensive and difficult to achieve [9]. A review of the CAFE program is scheduled for 2018 , and many believe that the standards may be scaled back at that point.
$\$ 200$ billion. The results confirm that the US economy could achieve a $50 \%$ GHG reduction by 2035 for about the same cost as the shale expansion benefits.

Table 5. Changes in Welfare with Respect to Changes in Emissions Reduction Target

\begin{tabular}{|c|c|c|c|c|c|}
\hline Description & \multicolumn{5}{|c|}{ Emission Reduction Target for 2035 } \\
\hline $\begin{array}{c}\text { Emissions reduction } \\
\text { target (\%) }\end{array}$ & 0 & 15 & 30 & 45 & 60 \\
\hline $\begin{array}{c}\text { Average annual welfare } \\
\text { changes compared with } \\
2007 \text { in billion dollar }\end{array}$ & 302 & 233 & 159 & 42 & -158 \\
\hline $\begin{array}{c}\text { Change in welfare for } \\
15 \% \text { increments in } \\
\text { emission reduction } \\
\text { Target }\end{array}$ & -69 & -74 & -117 & -200 \\
\hline
\end{tabular}

Simulation results represent changes in welfare (measured in terms of Equivalent Variation) with respect to changes in emissions reduction targets (implemented by using an emissions tax for each target) in the presence of expansion in using shale oil and gas resources. Welfares changes represent average change for the time period of 2008-2035 compared with the base year of 2007 .

We now summarize the key results. Figure 4 provides a comparison of the welfare gain and GDP impacts under the alternative policies. In all cases there is a welfare gain for the US economy with positive impact on GDP. For the shale expansion only, the gain is on average $\$ 302$ billion/year and an improvement in real annual GDP by $2.2 \%$. In the other three cases there is a lower economic gain (and lower GDP gains) that can be measured but also a substantial gain in reduction in GHG emissions. Clearly the carbon tax it the most efficient means of accomplishing that GHG reduction. Case 3 with all the reduction coming from transportation and electricity costs the US economy about $\$ 30$ billion/year compared with the carbon tax approach. As would be expected, an economy-wide carbon tax that spreads the cost of emission reductions and achieves the reductions at lowest cost to the economy is the most efficient.

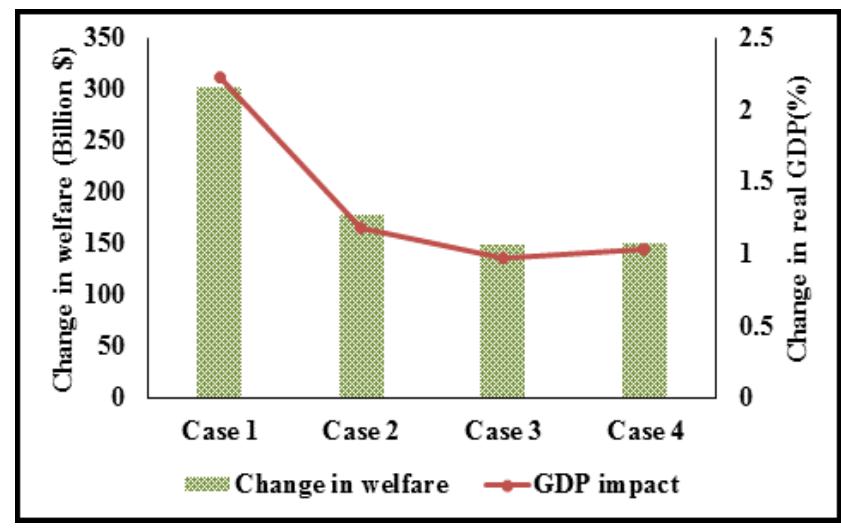

Figure 4. Changes in welfare due to expansion in using shale resources under alternative cases

Coal and electricity output and prices are significantly impacted by the policy differences as illustrated in Figures 5 and 6 . With shale expansion alone electricity output actually grows a bit while price declines. For coal there is almost no change with shale expansion alone. The big changes, of 
course, occur with the emission policy implementations. Electricity output declines, and price increases under all three policy options with the largest changes under the policy targeted at electricity exclusively, and the smallest for the economy-wide carbon tax. Interestingly, oil and natural gas prices decline about the same under all policy measures. Basically, the decline in income would depress prices, but the emission's policies would increase them, so the two effects basically offset each other. Most of the other price and quantity changes move in the directions one would expect.

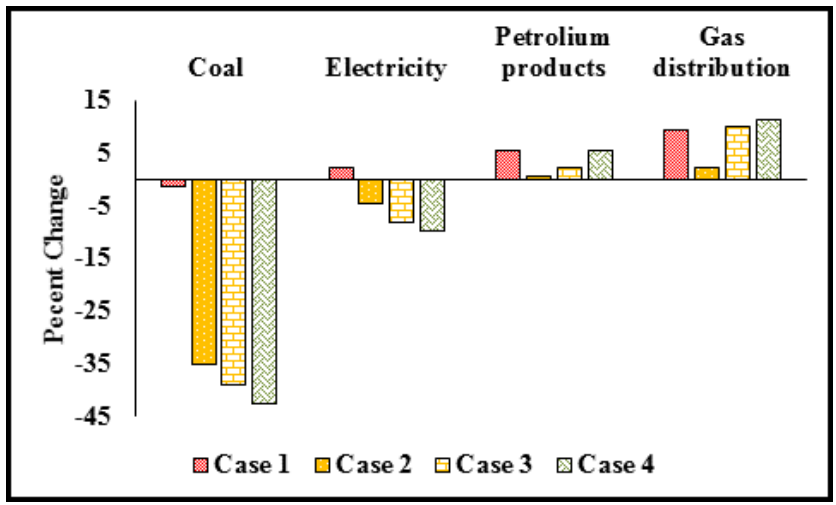

Figure 5. Changes in supplies of energy items under alternative cases
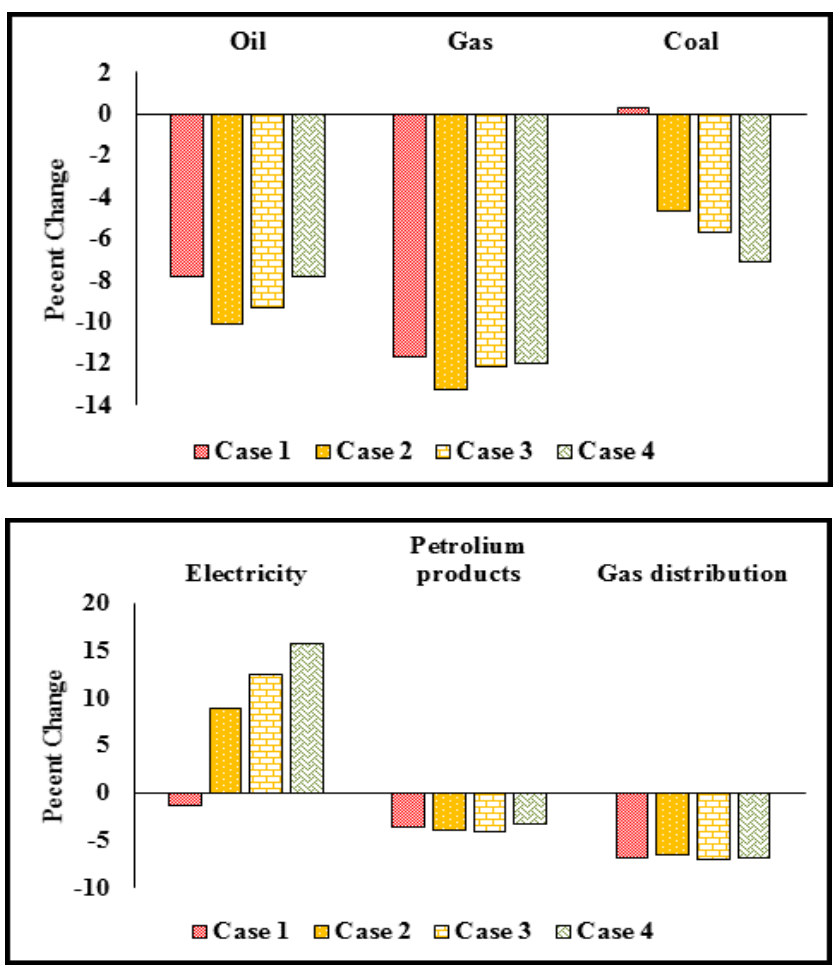

Figure 6. Changes in supply prices of energy items under alternative cases

\section{Conclusions}

The shale oil and gas economic gains are larger than the costs of reducing GHG emissions. Of course, some will argue that we should forego the shale oil and gas and achieve the GHG reductions regardless of the cost to the economy. What we have attempted to do here is to highlight the alternative policy options and the consequences of each. The shale "dividend" is large, and it was for the most part unanticipated a decade ago. Should we only use these new sources for higher economic growth or should part of it be allocated towards reducing future global warming. In fact, the sensitivity analysis developed in this paper shows that the US could achieve 50\% GHG reduction if it chose to "spend" the gains from shale expansion in this way. Clearly, the US has a choice in how it "spends" the shale dividend. If it so chooses, it can have both significant economic benefits from shale oil and gas plus environmental benefits from $\mathrm{GHG}$ reduction.

\section{Acknowledgements}

This research was done at Purdue University with no external funding.

\section{Appendix}

\section{Appendix A: Modifications in GTAP data base version 8}

Following a detective work we realized the GTAP data base version 8 suffers from major deficiencies in representing monetary values associated with the "gas" and "gdt" sectors and in particular ignores gas sales from "gas" to "gdt" for distribution. This Appendix outlines these deficiencies and implements several steps to fix them.

\section{Production and distribution of GAS in GTAP database version 8}

To examine the data base we begin with provided information on consumption and trade of "gas" and "gdt" in millions of tonnes of oil equivalent (Mtoe) as shown in Table A1. This table shows that the US consumption of gas (imported and domestic gas distributed by "gas" and "gdt" sectors and used by industries and households) was about 610.7 Mtoe in 2007. This figure is not very different from the corresponding figure reported by the DOE for this year, 596.2 Mtoe.

This table also shows that about 113.5 Mtoe of the distributed gas in US in 2007 is used by households. Again this figure is not very different for the corresponding figure reported by the DOE (i.e. 121.9 Mtoe). These comparisons indicate that the GTAP data base fairly represents the amount of gas used in US. Since the source of GTAP on energy is IEA, we can trust GTAP figures on consumed gas for other regions as well. However, as explained later in this section, the GTAP data base does not appropriately represent values of gas produced and consumed. In addition it misrepresents the link between the "gas" and "gdt" sectors in the regional input-output (I-O) tables. 
Table A1. Consumption of gas by industry and household in 2007 (Mtoe)

\begin{tabular}{|c|c|c|c|c|c|c|c|c|c|c|}
\hline \multirow{2}{*}{\multicolumn{2}{|c|}{ Description }} & \multicolumn{3}{|c|}{ Gas used by industry } & \multicolumn{3}{|c|}{ Gas used by household } & \multicolumn{3}{|c|}{ Total gas used } \\
\hline & & US & Non US & Total & US & Non US & Total & US & Non US & Total \\
\hline \multirow{2}{*}{ Domestic } & Gas & 81.6 & 888.0 & 969.6 & 0.0 & 20.1 & 20.1 & 81.6 & 908.1 & 989.8 \\
\hline & Gdt & 305.3 & 516.8 & 822.1 & 108.7 & 194.7 & 303.5 & 414.0 & 711.5 & 1125.5 \\
\hline \multirow{2}{*}{ Imported } & Gas & 109.2 & 484.5 & 593.7 & 0.0 & 55.0 & 55.0 & 109.2 & 539.4 & 648.7 \\
\hline & Gdt & 1.0 & 59.2 & 60.2 & 4.7 & 39.3 & 44.1 & 5.8 & 98.5 & 104.3 \\
\hline \multicolumn{2}{|c|}{ Total } & 497.2 & 1948.3 & 2445.6 & 113.5 & 309.2 & 422.7 & 610.7 & 2257.6 & 2868.2 \\
\hline
\end{tabular}

Source: GTAP data base headers obtained from CEDF, CEIF, CEDP, and CEIP headers.

To determine the source of these issues consider now another aspect of the data on gas consumed in US as shown in Table A2. In this table the intermediate consumption of gas (sold either by "gas" or "gdt") are divided into gas used by "gdt" and "non-gdt" sectors. This table shows that the "gdt" sector (as a gas using industry) is used 27.5 Mtoe gas. On the other hand this sector (i.e. "gdt") sold 419.8 Mtoe of gas as a gas seller. Since "gdt" does not use resources to produce gas, this shows that transferred gas from "gas" sector to "gdt" sector is not included in the GTAP energy data in physical terms. Of course nothing is wrong here if we use this information to represent the net use of gas (as a source of energy) by sector. However, as it is evident from the GTAP regional I-O tables, if we use this data to measure the value of gas sold to the "gdt" sector in I-O tables, then the results will be misleading.

Table A2. US consumption of gas by major users in 2007 (Mtoe)

\begin{tabular}{rccccc}
\hline \multirow{2}{*}{ Description } & \multicolumn{3}{c}{ Intermediate } & & \\
\cline { 2 - 5 } & & $\begin{array}{c}\text { Used in } \\
\text { gdt }\end{array}$ & $\begin{array}{c}\text { Used in } \\
\text { Non-gdt }\end{array}$ & Household & Total \\
\hline \multirow{2}{*}{ Domestic } & gas & 13.8 & 67.8 & 0.0 & 81.6 \\
\cline { 2 - 6 } & gdt & 9.9 & 295.4 & 108.7 & 414.0 \\
\hline \multirow{2}{*}{ Imported } & gas & 3.8 & 105.4 & 0.0 & 109.2 \\
\cline { 2 - 5 } & gdt & 0.0 & 1.0 & 4.7 & 5.8 \\
\hline Total & & 27.5 & 469.7 & 113.5 & 610.7 \\
\hline
\end{tabular}

According to the GTAP data base the value of gas sold to "gdt" in US (VDFM + VIFM) in 2007 is about $\$ 4.8$ billion. This is about the value of net gas used in "gdt" as a source of energy (27.5 Mtoe reported in Table A2). This indicates that the US I-O table is missing the value of gas transferred from "gas" to "gdt" for distribution. The I-O tables of other regions suffer from the similar deficiency as well. Because of this deficiency, the cost share of gas in the cost structure of "gdt" is negligible in many regions in the GTAP data base as shown in Table A3. This deficiency undermines the linkages between the "gas", "gdt", and other sectors and badly affects the credibility of GTAP simulation results in response to the expansion in gas industry.

The GTAP data base version 8 misrepresents the monetary value of gas used by households also. As shown in tables A1 and A2, the GTAP data base shows that US households used about 113.5 Mtoe gas (gas plus gdt) in 2007. This is not very different for the corresponding figure reported by the DOE. However, the GTAP data base shows that US households purchased about $\$ 30$ billion gas (domestic plus imported "gas" and "gdt") in 2007, and this is very different from the corresponding reported value by DOE which is about $\$ 62$ billion. This simple comparison shows that the GTAP data base badly underestimates values of gas used by households. Missing the value of gas transferred from "gas" to "gdt" causes this issue as well.

Table A3. Share of gas in the cost structure of "gdt" in GTAP data base version 8 by region

\begin{tabular}{ccccc}
\hline USA & EU27 & BRAZIL & CAN & JAPAN \\
\hline 4.4 & 5.8 & 53.1 & 1.5 & 1.1 \\
\hline CHIHKG & INDIA & C_C_Amer & S_o_Amer & E_Asia \\
\hline 15.2 & 0.3 & 27.8 & 13 & 10.4 \\
\hline Mala_Indo & R_SE_Asia & R_S_Asia & Russia & Oth_CEE_CIS \\
\hline 3.3 & 8.3 & 1.2 & 0.7 & 10.5 \\
\hline Oth_Europe & MEAS_NAfr & S_S_AFR & Oceania & \\
\hline 5.7 & 3.8 & 9.9 & 11.3 &
\end{tabular}


In addition to the above problems the split of gas between "gas" and "gdt" is counter intuitive. In general, the gas industry (including production and distribution) produces gas and sells it to major users such as power plants, major industries, commercial users, and households. In this process major users such as power plants and industries pay lower prices, and the commercial users and households pay a higher price. In general, the commercial and household users pay more because the distribution of gas through pipeline is costly. Now consider the implicit regional prices of gas sold by "gas" and "gdt" sectors, both obtained from the GTAP data base and presented in table A4. This table shows that the US implicit prices of gas sold by "gas" and "gdt" are about $304 \$$ /toe and 269 \$/toe with an average of $275 \$ /$ toe. According to the DOE data bases the US gas prices for household and power plants were about 507 \$/toe and \$283 \$/toe, respectively, with an average of $359 \$ /$ toe in 2007. These figures show that the price of gas sold to households is much higher than the price of gas sold to power plants. But in
GTAP the price of gas sold by "gas" is much higher than the price of gas sold by "gdt". In addition, these figures indicate that the GTAP implicit average price of gas is significantly below the actual average price of gas in US. Table A4 shows that the relationship between the gas prices sold by "gas" and "gdt" in some regions (e.g. EU and Canada) is consistent with what we expect to observe.

In conclusion, the above analyses indicate that:

- The GTAP data base ignores the link between "gas" and "gdt" and does not capture the values of gas sold from "gas" to "gdt" for distribution,

- The GTAP data base underestimates gas values used by commercial firms and households,

- The "gas" and "gdt" sectors in GTAP do not properly represent the production and distribution of gas as they operate in world.

Since these issues could affect the GTAP simulation results we modify the GTAP data base as outlined in the next sections.

Table A4. Implicit prices of gas sold by "gas" and "gdt" (values are in \$/toe)

\begin{tabular}{|c|c|c|c|}
\hline Region & implicit price of gas sold by "gas" & implicit price of gas sold by "gdt" & Average implicit price of gas \\
\hline USA & 304.1 & 269.1 & 274.9 \\
\hline EU27 & 623.2 & 303.9 & 371.3 \\
\hline BRAZIL & 169.7 & 172.5 & 170.7 \\
\hline CAN & 509.2 & 216.1 & 468.4 \\
\hline JAPAN & 310.3 & 310.3 & 310.3 \\
\hline CHIHKG & 98.9 & 115.1 & 106.7 \\
\hline INDIA & 236.2 & 236.3 & 236.3 \\
\hline C_C_Amer & 318.0 & 198.4 & 249.8 \\
\hline S_o_Amer & 106.0 & 71.2 & 90.4 \\
\hline E_Asia & 123.7 & 416.8 & 237.9 \\
\hline Mala_Indo & 685.5 & 222.6 & 419.3 \\
\hline R_SE_Asia & 877.7 & 301.5 & 403.1 \\
\hline R_S_Asia & 289.1 & 286.7 & 287.4 \\
\hline Russia & 147.5 & 260.6 & 180.9 \\
\hline Oth_CEE_CIS & 487.4 & 303.9 & 395.0 \\
\hline Oth_Europe & 1475.7 & 396.1 & 1446.1 \\
\hline MEAS_NAfr & 335.9 & 150.7 & 266.9 \\
\hline S_S_AFR & 613.9 & 225.5 & 474.1 \\
\hline Oceania & 496.1 & 235.2 & 369.5 \\
\hline
\end{tabular}




\section{Corrections in gas and gdt sectors}

Step 1: In this step we pooled the "gas" and "gdt" together and created a new sector which covers both production and distribution of gas. In addition, regions are aggregated to 19 categories following the GTAP-BIO model aggregation scheme. The FlexAgg program is used in this step.

Step 2: Then we made the following adjustment in the data base with the pooled gas and gdt activities:

a. The GTAP regional values of gas sold to commercial users (services) and households are corrected according and the available data. We used the GTAPAdjust program to introduce the corrected values in the data base and maintain its balances.

b. The modified gas sector is divided into two sectors of "Gas" and "Gas-D" so that the former sells gas to industries, and the latter sells gas to services and households. The Split.com program is used to accomplish this task.

c. The values of gas sold from "Gas" to Gas-D" in each region are estimated and included in the data base, again using the GTAPAdjust program.

The regional market values of gas sold by "Gas-D" inflated by $65 \%$ to represent the price difference between the price of gas for industries and commercial firms and household. The GTAPAdjust is used several times to handle this modification and reconstruct the cost structures of the new "Gas" and "Gas-D" sectors.

\section{Appendix B: Original and modified production functions}

Table B1. A representative production function in original GTAP-E original model

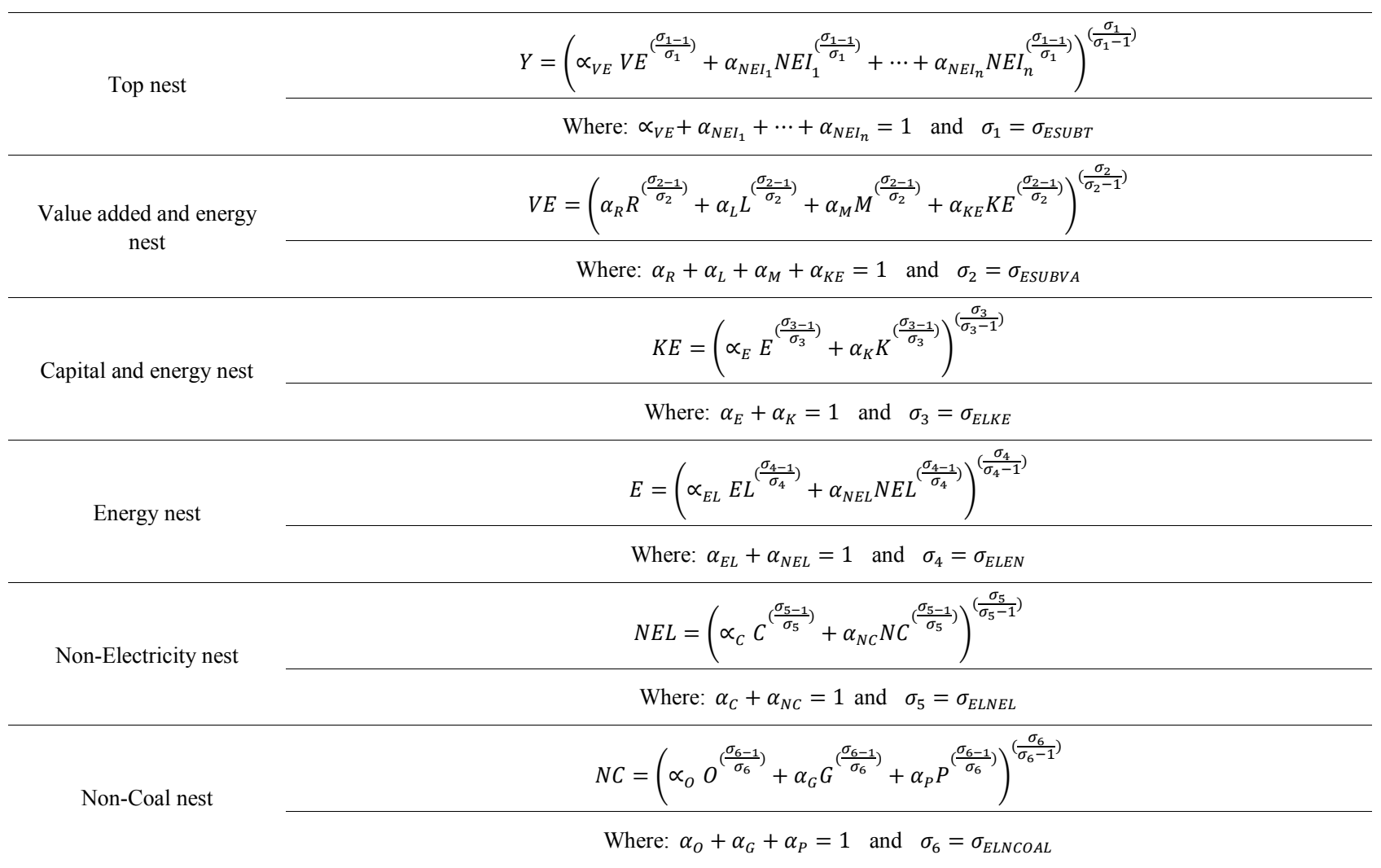

Definitions: The variables and parameters used in the above equations are: $\alpha_{i}$ 's represent share parameters; $\sigma_{i}$ 's show substitution elasticities; variables $\mathrm{O}, \mathrm{G}, \mathrm{P}, \mathrm{C}$, and EL demonstrate energy inputs including crude oil, gas, petroleum products, coal, and electricity, respectively; variables R, $\mathrm{L}, \mathrm{M}, \mathrm{K}$ stand for primary inputs including resources, labor, land, and capital, respectively; $\mathrm{NEI}_{\mathrm{i}}$ 's presents non-energy intermediate inputs; and finally $\mathrm{Y}$ is the final output. 
Table B2. A representative production function in modified GTAP-E original model

\begin{tabular}{|c|c|}
\hline Top nest & $Y=\left(\propto_{V E} V E^{\left(\frac{\sigma_{1-1}}{\sigma_{1}}\right)}+\alpha_{N E I_{1}} N E I_{1}^{\left(\frac{\sigma_{1-1}}{\sigma_{1}}\right)}+\cdots+\alpha_{N E I_{n}} N E I_{n}^{\left(\frac{\sigma_{1-1}}{\sigma_{1}}\right)}\right)^{\left(\frac{\sigma_{1}}{\sigma_{1}-1}\right)}$ \\
\hline & Where: $\propto_{V E}+\alpha_{N E I_{1}}+\cdots+\alpha_{N E I_{n}}=1$ and $\sigma_{1}=\sigma_{E S U B T}$ \\
\hline \multirow{2}{*}{$\begin{array}{c}\text { Value added and energy } \\
\text { nest }\end{array}$} & $V E=\left(\alpha_{R} R^{\left(\frac{\sigma_{2-1}}{\sigma_{2}}\right)}+\alpha_{L} L^{\left(\frac{\sigma_{2-1}}{\sigma_{2}}\right)}+\alpha_{M} M^{\left(\frac{\sigma_{2-1}}{\sigma_{2}}\right)}+\alpha_{K E} K E^{\left(\frac{\sigma_{2-1}}{\sigma_{2}}\right)}\right)^{\left(\frac{\sigma_{2}}{\sigma_{2}-1}\right)}$ \\
\hline & Where: $\alpha_{R}+\alpha_{L}+\alpha_{M}+\alpha_{K E}=1$ and $\sigma_{2}=\sigma_{E S U B V A}$ \\
\hline \multirow[t]{2}{*}{ Capital and energy nest } & $K E=\left(\alpha_{E} E^{\left(\frac{\sigma_{3-1}}{\sigma_{3}}\right)}+\alpha_{K} K^{\left(\frac{\sigma_{3-1}}{\sigma_{3}}\right)}\right)^{\left(\frac{\sigma_{3}}{\sigma_{3}-1}\right)}$ \\
\hline & Where: $\alpha_{E}+\alpha_{K}=1$ and $\sigma_{3}=\sigma_{E L K E}$ \\
\hline \multirow[t]{2}{*}{ Energy nest } & $E=\left(\propto_{E L} E L^{\left(\frac{\sigma_{4-1}}{\sigma_{4}}\right)}+\alpha_{N E L} N E L^{\left(\frac{\sigma_{4-1}}{\sigma_{4}}\right)}\right)^{\left(\frac{\sigma_{4}}{\sigma_{4}-1}\right)}$ \\
\hline & Where: $\alpha_{E L}+\alpha_{N E L}=1$ and $\sigma_{4}=\sigma_{E L E N}$ \\
\hline \multirow{2}{*}{$\begin{array}{c}\text { Coal-Gas and } \\
\text { Oil-Petroleum nest }\end{array}$} & $N E L=\left(\alpha_{C G} C G^{\left(\frac{\sigma_{5-1}}{\sigma_{5}}\right)}+\alpha_{O P} O P^{\left(\frac{\sigma_{5-1}}{\sigma_{5}}\right)}\right)^{\left(\frac{\sigma_{5}}{\sigma_{5}-1}\right)}$ \\
\hline & Where: $\alpha_{C G}+\alpha_{O P}=1$ and $\sigma_{5}=\sigma_{E L C G O P}$ \\
\hline Coal and gas nest & $C G=\left(\propto_{C} C^{\left(\frac{\sigma_{6-1}}{\sigma_{6}}\right)}+\alpha_{G} G^{\left(\frac{\sigma_{6-1}}{\sigma_{6}}\right)}\right)^{\left(\frac{\sigma_{6}}{\sigma_{6}-1}\right)}$ \\
\hline
\end{tabular}

Definitions: The variables and parameters used in the above equations are: $\alpha_{i}$ 's represent share parameters; $\sigma_{\mathrm{i}}$ 's show substitution elasticities; variables G, C, OP and EL demonstrate energy inputs including gas, coal, oil and petroleum products, and electricity, respectively; variables R, L, M, $\mathrm{K}$ stand for primary inputs including resources, labor, land, and capital, respectively; $\mathrm{NEI}_{\mathrm{i}}$ 's presents non-energy intermediate inputs; and finally $\mathrm{Y}$ is the final output.

\section{REFERENCES}

[1] Advanced Resources International. EIA/ARI World shale sas and shale oil resource assessment, Advanced Resources International Inc. Arlington, VA, USA, 2013.

[2] U.S. Department of Energy. Annual energy outlook. Washington DC, USA, 2013.

[3] S. Brown, S. Gabriel, R. Egging. Abundant shale gas resources: Some implications of energy policy, Resources for the Future. USA, 2010.

[4] S. Paltsev, D. Jacoby, J. Reilly, Q. Ejaz, F. O'Sullivan, J. Morris, S. Rausch, N. Winchester, O. Kragha. The future of U.S. natural gas production, use, and trade, Energy Journal, 39: 5309-5321. 2011.

[5] D. Jacoby, F. O'Sullivan, S. Paltsive. The influence of shale gas on U.S. energy and environmental policy, MIT Joint Program on the Science and Policy of Global Change, USA, 2012.

[6] IHS Global Insight. The economic and employment contributions of shale gas in the United States, IHS Global Insights (USA) Inc., Washington DC, USA, 2011.

[7] Citi GPS. Energy 2020: North America, the new Middle East?
Citi GPS: Global Perspecitves and Solutions, 2012.

[8] V. Arora. Aggregate impacts of recent U.S. ratural gas trends. U.S. Department of Energy, Washington DC, USA, 2013

[9] K. Sarica, W. Tyner. Alternative policy impacts on US GHG emissions and energy security: A hybrid modeling approach, Energy Economics, 40:40-50, 2013.

[10] F. Taheripour, W. Tyner, K. Sarica. Shale gas boom, trade and environmental policies: Global economic and environmental analyses in a multidisciplinary modeling framework, In R.E. Hester, and R. Harrison eds. Issues in Environmental Science and Technology, Vol. 39 Fracking, Cambridge, UK, Royal Society of Chemistry, 2014.

[11] T. Hertel. Global trade analysis, modeling and applications, Cambridge University Press, Cambridge, UK, 1997.

[12] J.Burniaux, T. Truong. GTAP-E: An energy-environmental version of the GTAP model, GTAP technical paper No. 16, Center for Global Trade Analysis, Purdue University, West Lafayette, IN, USA, 2002.

[13] R. McDougall, A. Golub. GTAP-E release 6: A revised energy-environmental version of the GTAP model, GTAP Technical Paper No. 15, Center for Global Trade Analysis, Purdue University, West Lafayette, IN, USA, 2007.

[14] F. Taheripour, D. Birur, T. Hertel, W. Tyner. Introducing liquid biofuels into the GTAP database, GTAP Research Memorandum No. 11, Purdue University, West Lafayette, IN, 
USA, 2007.

[15] T. Hertel, A. Golub, A. Jones, M. O'hare, R. Plevin, D. Kammen. Effects of US maize ethanol on global land use and greenhouse gas emissions: Estimating market-mediated responses, Bioscience 60(3), 223-231, 2010.

[16] Energy Information Administration. Emissions of greenhouse gases in the United States 2009, U.S. Department of Energy, Washington, DC, USA, 2011.
[17] B. Narayanan, A. Aguiar, R. McDougall. Global Trade, Assistance, and Production: The GTAP 8 Data Base, Center for Global Trade Analysis, Purdue University, West Lafayette, IN, USA, 2012.

[18] K. Huff, T. Hertel . Decomposing Welfare Changes in the GTAP Model, GTAP Technical Paper No. 5, Center for Global Trade Analysis, Purdue University, West Lafayette, IN, USA, 2000. 